\title{
A APLICABILIDADE DA TEORIA DO DIREITO SOCIAL DE GURVITCH NO RECONHECIMENTO DE DIREITOS HUMANOS DE CRIANÇAS E ADOLESCENTES: ESTRATÉGIAS PARA O ENFRENTAMENTO AO TRABALHO INFANTIL NOS MUNICÍPIOS BRASILEIROS ${ }^{1}$
}

\author{
Rafael Bueno da Rosa Moreira ${ }^{2}$ \\ André Viana Custódio ${ }^{3}$
}

\section{RESUMO:}

O objetivo da pesquisa foi verificar a aplicabilidade da teoria do direito social de Gurvitch no desenvolvimento de políticas públicas e no reconhecimento de direitos humanos inerentes à infância para o enfrentamento ao trabalho infantil. O problema de pesquisa utilizado foi: como pode ser utilizado a teoria do direito social de Gurvitch no enfrentamento ao trabalho infantil nos municípios brasileiros? Foi realizada pesquisa bibliográfica, utilizando do método de procedimento analítico e do método de abordagem dedutivo. Constatou-se que o direito social condensado poderá ser utilizado quando observado o referencial mínimo constitucional, o que possibilitaria a participação social nas decisões públicas.

Palavras- chave: direito social; trabalho infantil; criança e adolescente.

\section{THE APPLICABILITY OF GURVITCH'S THEORY OF SOCIAL LAW IN THE DEVELOPMENT OF HUMAN RIGHTS OF CHILDREN AND ADOLESCENTS: STRATEGIES FOR FACING CHILD LABOR IN BRAZILIAN MUNICIPALITIES}

\begin{abstract}
The present paper had as main objective to verify the applicability of Gurvitch 's social law theory in the development of public policies and in the constitution of human rights inherent to childhood to confront child labor. The research problem was: how can Gurvitch's social law theory be used in confronting child labor in Brazilian municipalities? A bibliographic research was carried out, using the method of analytical procedure and the method of deductive approach. It was found that the condensed social law can be used when observing the minimum constitutional reference, which would allow social participation in public decisions.
\end{abstract}

Keywords: social law; Child labor; child and adolescents.

\section{CONSIDERAÇÕES INICIAIS}

\footnotetext{
${ }^{1}$ Este estudo é o resultado de pesquisas feitas junto ao Programa de Doutorado da Universidade de Santa Cruz do Sul-UNISC, visando o desenvolvimento de tese de doutoramento.

${ }^{2}$ Doutorando e Mestre em Direito pela Universidade de Santa Cruz do Sul (UNISC), integrante do Grupo de Estudos em Direitos Humanos de Crianças e Adolescentes (GRUPECA/UNISC) e do Grupo de Pesquisa Políticas Públicas de Inclusão Social (UNISC). Professor do Curso de Graduação em Direito da Universidade da Região da Campanha - URCAMP/ Bagé. Coordenador do Projeto de Pesquisa sobre Trabalho Infantil e Políticas Públicas para o seu enfrentamento no município de Bagé-RS (URCAMP) e do Grupo de Estudos em Direitos Humanos de Crianças e Adolescentes nos países do MERCOSUL (GEDIHCA/URCAMP). Endereço eletrônico: rafaelbmoreira2@yahoo.com.br.

${ }^{3}$ Pós-Doutor em Direito pela Universidade de Sevilha - Espanha, Mestre e Doutor em Direito pela Universidade Federal de Santa Catarina (UFSC), Professor do Programa de Mestrado e Doutorado em Direito da Universidade de Santa Cruz do Sul (UNISC), Coordenador do Grupo de Estudos em Direitos Humanos de Crianças, Adolescentes e Jovens (GRUPECA/UNISC) e Pesquisador do Grupo de Pesquisa Políticas Públicas de Inclusão Social (UNISC). Endereço eletrônico: andreviana.sc@gmail.com.
} 


\section{A aplicabilidade da teoria do direito social de Gurvitch no reconhecimento de direitos humanos de crianças e adolescentes: estratégias para o enfrentamento ao trabalho infantil nos municípios brasileiros}

A teoria do direito social de Gurvitch possui o intuito de buscar um modelo alternativo aos clássicos referencias teóricos do direito. É uma teoria que prima pela participação comunitária nas decisões relacionadas ao direito em um determinado local.

Com o desenvolvimento do artigo, buscou-se analisar a utilização do direito social de Gurvitch no enfrentamento ao trabalho infantil nas esferas municipais, verificar a teoria do direito social, o procedimentalismo, o substancialismo, o trabalho infantil, seus mitos e consequências e demonstrar o papel dos Conselhos Municipais de Direitos da Criança e Adolescente na erradicação ao trabalho infantil.

A abordagem teórica sobre o tema proposto se justifica em face da relevância em se buscar estratégias para enfrentar a violação de direitos humanos de crianças e adolescentes que decorre da exploração do trabalho infantil, possibilitando concluir sobre o papel dos Conselhos de Direitos da Criança e do Adolescente nos municípios brasileiros.

A presente pesquisa científica buscou responder o seguinte problema: como pode ser utilizado a teoria do direito social de Gurvitch no enfrentamento ao trabalho infantil nos municípios brasileiros?

Para a obtenção de tais dados, foi realizada uma pesquisa bibliográfica e jurisprudencial, utilizando do método de abordagem dedutivo e do método de procedimento analítico.

\section{A TEORIA DO DIREITO SOCIAL DE GURVITCH}

A teoria do direito social, proposta por Gurvitch, baseia-se em uma nova categoria de direito que busca atender as necessidades jurídicas contemporâneas, utilizando conceitos distintos dos modelos tradicionais teóricos de direito. Buscou-se construir uma nova ideia de direito que pudesse estar adequada a realidade social e ao tempo atual (2005, p. 03-06)

O direito social se opõe aos modelos teóricos de individualismo jurídico, se baseando na superação do individual em busca do social, tendo a finalidade de substituir os sistemas tradicionais e conservadores. Portanto, o direito social se distinguiu das concepções individuais de direito e de suas características, que foram muito utilizadas no decorrer da história nos sistemas jurídicos nacionais. (GURVITCH, 2005, p. 07-18). 
Além de se opor ao individualismo jurídico, o direito social também realizou um contraponto a univocidade estatal. Foi proposto um modelo que era contrário a posturas individualistas e estatalistas. Pode-se dizer que o direito social proposto por Gurvitch é uma espécie de direito que se encontra entre o individualismo liberal e o universalismo socialista, estando relacionado ao grupo social no qual os sujeitos integram, sendo um direito para o grupo social e não para o indivíduo, tendo características comunitárias e visando o bem comum do grupo. O direito social não se limita a ideia de política social do Estado, com regras utilizadas somente para regular os direitos sociais, ele é muito mais amplo e tem por objetivo a criação das regras jurídicas pela totalidade dos membros de determinado grupo social (MORAES, 1997, p. 29-33).

O direito social é um direito que é "[...] produzido pela própria sociedade, uma regulação autônoma de cada grupo, alheia ao direito estatal" (MORAES, 1997, p. 35).

Suas características são próprias, podendo se destacar todas aquelas que fazem oposição aos modelos que foram postos até o seu surgimento, que tinham raízes distintas. $\mathrm{O}$ direito social se desenvolve com a perspectiva de integração entre os sujeitos da sociedade, havendo atuações em sua totalidade, contribuindo em comunhão para o grupo e havendo uma participação mútua. É necessário para o êxito do direito social estar implícito nos sujeitos da sociedade que o ideal social deve estar acima dos interesses individuais. Assim, a integração social deverá ocorrer por meio de movimentos entre os atores sociais, se primando pela integração de membros no todo. Se prima pela participação de todos de forma recíproca (GURVITCH, 2005, p. 20-23).

Já as obrigações que surgem com o direito social devem ser extraídas da totalidade de pessoas, elas que são a autoridade. O direito social surge do todo em um grupo para todos os integrantes de um grupo, por isso ele é denominado como um direito de integração. A regulamentação da vida em sociedade pelo direito social surge da integração da totalidade do grupo que deve agir em comunhão. Busca-se a participação direta da totalidade dos membros de um grupo de forma espontânea, para que seja respeitado o que for decidido por todos, mesmo contra a sua vontade. A construção do direito social se limita ao grupo em que se está desenvolvendo as atividades. Já a integração da totalidade do grupo, mediante a unidade do todo, se dá pelo "poder social" que é exercido sobre a totalidade dos membros (GURVITCH, 2005, p. 23-27). 


\section{A aplicabilidade da teoria do direito social de Gurvitch no reconhecimento de direitos humanos de crianças e adolescentes: estratégias para o enfrentamento ao trabalho infantil nos municípios brasileiros}

O direito social não organizado se sobrepõe ao direito social organizado, pois a não organização é que possibilita a integração e participação da totalidade do grupo na construção do direito. A participação se dá de forma voluntária, exercendo-se a cidadania, e há o intuito de garantir o interesse geral do grupo que está participando das deliberações sobre determinada temática. O direito social organizado, por sua vez, serve ao direito social não organizado, tendo limites para evitar a subordinação, a dominação e a exclusão de participação que podem surgir com as formas organizadas. Os sujeitos do direito social organizado são as pessoas coletivas complexas. Os sujeitos do direito social são distintos do direito individual, decorrendo de sistemas complexos representativos dos membros do grupo. As pessoas coletivas complexas buscam a colaboração entre os membros e não a dominação dos membros. Verifica-se que o direito social organizado visa trazer representatividade para o grupo que desenvolveu o direito social de uma forma não organizada em sua totalidade (GURVITCH, 2005, p. 27-40).

No direito social de Gurvitch, a sanção para o cumprimento do direito não é essencial para a repressão ao comportamento incorreto, se estando mais preocupado com a integração do grupo do que a coordenação do indivíduo. De forma resumida, o direito social tem por características ser: “(1) um direito de comunhão, (2) um direito de coletividades; (3) um direito interior, onde (4) Não há separação entre produtores e consumidores e (5) cuja efetividade não está atrelada à ideia de sanção incondicionada [...]” (MORAES, 1997, p. 37 40).

O respeito às normas pela sociedade é algo importante para que seja legitimada a construção do direito por meio do direito social, possibilitando que a sociedade, de forma espontânea, respeite o direito, havendo dispensa da necessidade de que se recorra à coação do Estado (MORAES, 1997, p. 41-42).

Em relação às classificações propostas em relação ao direito social, serão utilizadas na presente abordagem o direito social puro e o direito social condensado, espécies de direitos sociais entre as classificações realizadas pelo autor. Entre o direito social puro e independente e o direito social condensado, existe o direito social puro submetido a tutela do direito estatal e o direito social anexado pelo Estado, tipos de direito social que não serão objetos desse estudo em decorrência das especificidades buscadas nos outros ramos (GURVITCH, 2005, p. 60-104). 
O direito social é puro quando não recorre à coação condicionada, sendo independente ao direito estatal e se mantendo superior ou equivalente a tal (GURVITCH, 2005, p. 60).

A pureza do direito social poderá ser perdida quando ele for colocado em submissão ao direito estatal. Para o direito social puro não haverá uma sanção quando do descumprimento de uma norma. Já a independência seria em relação ao direito social puro ser independente do direito emanado pelo poder soberano estatal. O direito social puro é aquele que se mantém alheio ao poder estatal (MORAES, 1997, p. 50).

O direito social condensado é aquele que "[...] se vincula definitivamente à ordem normativa do Estado, sendo esta produto de uma organização igualitária de colaboração, não perdendo com isto sua feição de ordem normativa social, apesar de, em sendo uma ordem estatal [...]" (MORAES, 1997, p. 50).

No direito social condensado o Estado permanece com o monopólio da coação incondicionada. O direito é construído pelo grupo social, mas a tutela incondicionada permanece em poder do Estado. Há uma ligação do direito social com o Estado, não se mantendo a pureza (GURVITCH, 2005, p. 92-93).

Portanto, o direito social puro e independente é aquele que não se relaciona com o Estado, que foi criado pelo grupo social, sendo respeitado e aplicado pela comunidade. Já o direito social condensado é aquele que se relaciona com o Estado, sendo desenvolvido pelo grupo social, mas aplicado pelo Estado. Este permanece com o poder da coação incondicionada.

A utilização de modelos alternativos aos tradicionais no Brasil encontra fulcro na crise dos poderes institucionais, sendo necessárias novas teorias de direito. Por um lado, há a falta de legitimidade do Poder Legislativo e Executivo em suas decisões. Por outro, há um Poder Judiciário elitista e excludente, que não possibilita o acesso universal a população.

O Poder Judiciário passa por dificuldades estruturais, com falta de pessoal e de estrutura. No entanto, a conta é paga por toda a população nacional para um serviço que não está acessível a todos e que não cumpre com as suas finalidades, sendo extremamente burocrático, lento, formal, procedimental, mecânico e pouco democrático, estando distante do cidadão brasileiro e que, por tais motivos, não possibilita melhores formas para o tratamento e a resolução dos conflitos. A crise vem desde os bancos escolares, onde a maior parte das universidades mantém o conservadorismo para o ensino e se acentua na prática com 


\section{A aplicabilidade da teoria do direito social de Gurvitch no reconhecimento de direitos humanos de crianças e adolescentes: estratégias para o enfrentamento ao trabalho infantil nos municípios brasileiros}

profissionais que se apegam as formalidades em detrimento da justiça. (SPENGLER, 2014, p. 30-32).

A sociedade brasileira possui uma ideia irreal de que o Poder Judiciário poderá resolver todos os seus conflitos. Culturalmente vige a ideia de transferência da resolução do conflito para um terceiro, se esperando uma "solução" para o problema. Daí que surge a figura do "mito" do juiz, um personagem que possibilitaria uma solução quando todas as alternativas de resolução do problema falhassem, seria quase um herói que teria poderes para encontrar a solução. Assim, com essa esperança na figura do juiz, a busca pela própria solução dos conflitos vem perdendo força e vem havendo um aumento considerável do número de litigâncias (SPENGLER, 2014, p. 33-34).

Por tais razões, “[...] nasceu a ideia (o mito) de que o juiz dá conta de todos os problemas, que o Poder Judiciário encontra-se de portas abertas para o litígio de sorte que todos que demandarem encontrarão nele a resposta de seus anseios de justiça” (SPENGLER, 2014, p. 35).

No entanto, o juiz não dá conta de todos os problemas de forma justa, ele tão somente é aquele que vai dizer a última palavra em relação a lide, visando que não haja a propagação da violência em uma comunidade. Com a sua pronúncia a lide será terminada, porém nem sempre resolvida (RESTA, 2014, p.14).

O conceito de direito voltado para o crescimento econômico deve ser superado em âmbito global, para se buscar um direito voltado para a construção de uma sociedade mais justa e não mais voltada para a garantia dos "interesses econômicos". Assim, "Se o direito tem desempenhado uma função crucial na regulação das sociedades, qual a sua contribuição para a construção de uma sociedade mais justa?” (SANTOS, 2008, p. 20). Para a busca de uma sociedade mais justa, de suma importância é a emancipação social, fator que possibilitaria a formação de indivíduos com plena cidadania, sujeitos com a consciência de seus direitos e com a possibilidade de buscá-los. Isto só seria possível mediante o enfrentamento das condições de exclusão social, principalmente com a erradicação da fome e a efetivação do desenvolvimento educacional universal, assim como o acesso à justiça por parte desses cidadãos, fatores que contribuiriam para a revolução democrática de justiça (SANTOS, 2008, p. 20-24).

Para se concretizar a democracia, exige-se que os cidadãos possuam direitos de cidadania: "A revolução democrática da justiça que aqui vos propus é uma tarefa muito 
exigente, tão exigente quanto esta ideia simples e afinal tão revolucionária; sem direitos de cidadania efetivos a democracia é uma ditadura mal disfarçada" (SANTOS, 2008, p. 90).

Assim, destaca-se que a participação de cidadãos ativos na construção do direito social condensado contribuiria para um modelo moderno, democrático e de inclusão social, onde haveria protagonismo no desenvolvimento de justiça social. Com a participação da população mais ativamente na construção do direito por meio da teoria do direito social, haverá maiores possibilidades de efetivação da cidadania, o que tornará o sistema de justiça mais democrático.

\section{DIREITO SOCIAL, PROCEDIMENTALISMO E SUBSTANCIALISMO}

As garantias constitucionais poderão ser afetadas quando da produção do direito social for desvinculada aos órgãos oficiais, necessitando-se de um “[ [...] referencial mínimo capaz de garantir as conquistas sociais, sob pena de retorno ao paradigma liberal, deficitário em relação aos direitos prestacionais" (HERMANY, 2007, p. 36).

O direito social puro deverá ter como limites as garantias constitucionais, com o intuito de que seja evitado o retrocesso social em relação a garantias que estão asseguradas na Constituição Federal, em especial aos direitos fundamentais. As limitações constitucionais ao direito social trazem a possibilidade de uma maior participação social e controle das decisões públicas, sem que haja retrocessos em relação as garantias fundamentais que já estão constitucionalizadas. Portanto, o direito social deve ser compatível com as garantias constitucionais, possibilitando a vinculação do direito social ao Estado Democrático (HERMANY, 2007, p. 36-37).

O direito social condensado é o ramo do direito social que possibilita a regulamentação do sistema jurídico pela sociedade e de acordo com o ordenamento jurídico constitucional. No direito social condensado, os atores sociais deverão se basear na ideia de democracia para a consolidação do modelo proposto. A democracia será a base para a atuação dos atores sociais no direito social, trazendo sustentação para a participação de todos os membros da sociedade, atentando-se, também, para a dignidade da pessoa humana como preceito fundamental na construção do direito. O direito social e a democracia estão relacionados, e os agentes sociais poderão contribuir para a concretização dos princípios constitucionais (HERMANY, 2007, p. 37; 40-41). 
Portanto, é na perspectiva de gestão compartilhada e de apreensão do espaço público estatal pela sociedade que deve ser inserida a ideia de um direito social que compatibiliza a ampliação do espaço de atuação da sociedade civil nas decisões públicas, mantendo-se, por outro lado, como referencial mínimo, o conjunto de princípios constitucionais e outras estruturas representativas essenciais. (HERMANY, 2007, p. 41)

Com isso, surge uma nova perspectiva de articulação entre a sociedade, se utilizando do espaço não estatal e se baseia no direito social condensado, na democracia e nos princípios constitucionais.

A lógica da construção do direito, com base na participação efetiva do cidadão, é a principal característica do direito social condensado. A participação no processo de tomada de decisões públicas e de elaboração das normas é uma condição de cidadania, observando-se os preceitos da Constituição Federal para garantir um referencial constitucional mínimo. O modelo exposto está vinculado: “[...] à concepção habermasiana de ação comunicativa e ao fortalecimento dos atores sociais" (HERMANY, 2007, p. 43).

A visão do direito social condensado de Gurvitch se apoia na teoria da comunicação de Habermas, visando superar a ideia de produção normativa monopolizada pelos órgãos oficiais, fazendo com que a legitimidade do direito se dê na integração com a sociedade. $\mathrm{O}$ modelo de direito reflexivo, que se difere do direito positivo, baseia-se no pluralismo jurídico, sendo um sistema aberto em relação à tomada de decisões, com decisões públicas e com a participação articulada dos atores sociais, diferindo-se do sistema fechado, que é característico do positivismo. (HERMANY, 2007, p. 44-45).

Sobre o agir comunicativo, elucida-se:

Portanto, esse novo paradigma do agir comunicativo pressupõe um sentimento de solidariedade social, capaz de superar a concepção egocêntrica própria do individualismo liberal-burguês, assumindo destaque a ideia de cidadania, princípio essencial que informa a ordem jurídica brasileira (HERMANY, 2007, p. 46).

A solidariedade social e a cidadania possuem papel essencial na garantia da legitimação na construção do direito social condensado, sendo fundamental a comunicação e participação política dos atores sociais para tal obtenção. Pois, com o consenso obtido com o agir comunicativo o direito será reconhecido pela sociedade. A elaboração da norma no direito social condensado será realizada pela via da democracia direta, sendo resultado de um 
processo participativo e democrático, fazendo com que o direito tenha uma relação mais estreita com a sociedade (HERMANY, 2007, p. 46-47; 54).

É importante mencionar, que o direito social condensado não admite a possibilidade de retrocesso social e utilização de um modelo de direito de Estados liberais, mesmo quando houver a intenção por parte dos atores sociais. O reducionismo de direitos sociais, que é próprio da influência do mercado nas relações sociais (característico de um Estado liberal), poderia ocorrer quando da liberdade de vontade por parte dos atores sociais e deve ser evitado. A vontade dos atores deverá estar de acordo com os preceitos constitucionais, primando-se pela dignidade da pessoa humana e pela garantia dos direitos humanos, para evitar o retrocesso social ou a "ditadura da maioria". Portanto, a maioria não poderá criar normas em desacordo com a Constituição Federal. (HERMANY, 2007, p. 49-52).

A ideia de direito social condensado deve "[...] possuir um mínimo de vinculação com institutos estatais, restringindo a atuação discursiva dos atores sociais" (HERMANY, 2007, p. 53). A atuação da sociedade deverá encontrar limites nos princípios relacionados à promoção de direitos humanos e fundamentais de uma forma ampla e nos preceitos constitucionais (HERMANY, 2007, p. 53).

O direito social condensado potencializa os espaços de participação/articulação social, contribuindo para a efetivação de direitos relacionados a efetivação da cidadania e da democracia dentro de uma comunidade (HERMANY, 2007, p. 53).

O cidadão tem papel fundamental na construção do direito no modelo reflexivo, atuando efetivamente para a concretização constitucional, que será realizada por meio da democratização dos espaços decisórios. Esse modelo possibilitaria um número cada vez maior de pessoas participando da autolegislação, o que contribui para a legitimação democrática com uma base comunicativa habermasiana (HERMANY, 2007, p. 54-56).

$\mathrm{O}$ direito social condensado que assegura um referencial mínimo constitucional proposto por Hermany se encontra entre as concepções procedimentalistas, de Habermas, e substancialistas, de Streck. Habermas defende que a legitimidade de um novo modelo jurídico decorre da democracia procedimental, havendo a aproximação entre a "[...] concepção habermasiana de legitimidade e a proposta de construção de uma normatividade que não esteja vinculada exclusivamente às estruturas atinentes ao processo legislativo oficial" (HERMANY, 2007, p. 60-61). Assim, "trata-se de uma nova normatividade decorrente de processos de autorregulação, nos quais prepondera a lógica argumentativa, mediante a 


\section{A aplicabilidade da teoria do direito social de Gurvitch no reconhecimento de direitos humanos de crianças e adolescentes: estratégias para o enfrentamento ao trabalho infantil nos municípios brasileiros}

comunicação de caráter discursivo, fundamentais na busca do consenso social" (HERMANY, 2007, p. 61).

O procedimentalismo busca superar o modelo tradicional de produção normativa mediante a atuação da sociedade civil de forma democrática e legítima, utilizando da lógica discursiva por parte dos atores sociais, em uma articulação comunicativa, que prima pela solidariedade social cidadã em busca do bem comum. Os membros da sociedade passam a exercer uma função atuante e não mais de meros destinatários das normas. Para os procedimentalistas, a Constituição Federal deve ser observada quando da produção democrática das leis por parte da sociedade, mas não há espaço para a intervenção estatal (HERMANY, 2007, p. 62-67).

Já no caso da teoria substancialista, o Poder Judiciário realizará uma intervenção sempre que a Constituição Federal não for observada, se garantindo os preceitos constitucionais de forma irradiante no ordenamento jurídico (HERMANY, 2007, p. 69).

O processo de "[...] atribuição de sentido ao texto constitucional tem como atores principais o Judiciário ou a Sociedade, conforme se adote a postura, respectivamente, substancialista ou procedimentalista" (HERMANY, 2007, p. 75).

A tese substancialista: “[...] enfatiza o papel do Judiciário na concretização do paradigma do Estado Democrático de Direito" (HERMANY, 2007, p. 75). Já a tese procedimentalista: “[...] destaca a posição da sociedade na condição de comunidade de intérpretes, atuando a partir de uma articulação comunicativa habermasiana" (HERMANY, 2007, p. 75).

Em ambas as propostas, o texto constitucional assume papel de protagonista, pois a finalidade é assegurar os princípios constitucionais. A divergência entre as teorias é em relação a garantia da consolidação e a interpretação do texto constitucional. Os substancialistas adotam a necessidade da atuação do Poder Judiciário, enquanto os procedimentalistas defendem a comunidade de intérpretes como responsáveis (HERMANY, 2007, p. 75).

Portanto, a desigualdade social e os consequentes impactos dela na cidadania, geram dificuldades ao modelo procedimentalista, pois nas circunstâncias do modelo brasileiro é improvável a participação de pessoas em situação de exclusão social no processo democrático discursivo proposto por Habermas. Para Streck não basta a simples abertura dos espaços democráticos, pois a situação de desigualdade trará impactos à efetiva participação de pessoas 
nesses debates. Diante do contexto, o Poder Judiciário também tem que agir para a garantia de direitos substancias de pessoas, visando a garantia da dignidade da pessoa humana. Para Streck, a concepção de Habermas está condicionada a uma sociedade emancipada, com sujeitos autônomos e que consigam exercer as necessidades comunicativas sem constrangimento. Para ele, Habermas em sua teoria jamais se referiu a países como o Brasil (HERMANY, 2007, p. 76).

Hermany propõe um pluralismo metodológico de forma alternativa às duas teorias, adotando tanto a teoria procedimentalista quanto a teoria substancialista, pois:

\begin{abstract}
[...] a possibilidade de conciliação da articulação comunicativa com um mínimo referencial constitucional, garantido pelo Poder Judiciário e palas demais instituições estatais, mostra-se fundamental, propiciando uma abertura do espaço público estatal, condicionada aos referenciais constitucionais. Da mesma forma, se, por um lado, os ensinamentos de Habermas e sua lógica de democracia procedimentalista se mostram essenciais para a abertura do espaço público, a contribuição substancialista, por outro lado, especialmente em relação à força normativa da Constituição e à necessidade de atribuição de sentido ao seu texto, pela concretização dos princípios constitucionais, assume papel indispensável (HERMANY, 2007, p. 79).
\end{abstract}

Portanto, não basta que haja a participação dos atores sociais, se não houver a garantia dos valores substanciais, principalmente em um contexto de grandes desigualdades sociais. Assim, importante é a participação social na construção do direito, assim como fundamental é a garantia da Constituição e seus direitos fundamentais pelo Poder Judiciário (HERMANY, 2007, p. 79).

\title{
3.1 O DIREITO SOCIAL E O TRABALHO INFANTIL
}

O trabalho infantil é uma forma de exploração laboral de crianças e adolescentes que traz as mais diversas consequências negativas para o desenvolvimento integral durante a infância e possui uma difícil conceituação, que deve atentar para a legislação nacional e internacional, assim como para os planos e programas de erradicação/enfrentamento ao trabalho infantil. As bases teóricas para tal definição são: a Convenção 138 da Organização Internacional do Trabalho, que dispõe sobre a idade mínima para admissão ao trabalho; a Convenção 182 da Organização Internacional do Trabalho, que trata das piores formas de trabalho infantil e de medidas imediatas para a sua erradicação; a Convenção sobre Direitos da Criança da Organização das Nações Unidas; a Constituição da República Federativa do 


\section{A aplicabilidade da teoria do direito social de Gurvitch no reconhecimento de direitos humanos de crianças e adolescentes: estratégias para o enfrentamento ao trabalho infantil nos municípios brasileiros}

Brasil; o Estatuto da Criança e do Adolescente; a Consolidação das Leis Trabalhistas; o Plano Nacional de Prevenção e Erradicação do Trabalho Infantil e Proteção ao Adolescente Trabalhador; e o Programa Internacional para Erradicação do Trabalho Infantil da Organização Internacional do Trabalho (CUSTÓDIO; MOREIRA, 2015, p. 65-69).

De acordo com as bases conceituais expostas, verifica-se que "trabalho infantil" é toda atividade de trabalho exercida sem respeitar as idades mínimas para tal, podendo ter o viés econômico ou ser estratégia para a sobrevivência, com ou sem remuneração, desenvolvida por crianças ou adolescentes. As idades mínimas para o trabalho no Brasil se distinguem conforme a normatização da atividade, sendo proibida qualquer atividade relacionada ao trabalho a pessoas que possuam menos do que catorze anos de idade. A partir dos catorze anos de idade é permitido o trabalho no regime de aprendizagem, de acordo com a Lei 10.097, de 15 de dezembro de 2000, devendo ser observados os requisitos legais. Já a partir dos dezesseis anos de idade é permitido o trabalho em geral, desde que seja de acordo com os requisitos previstos em lei e não seja nenhuma atividade que só possa ser realizada a partir dos dezoito anos. E abaixo dos dezoito anos de idade é proibido o trabalho insalubre, perigoso, penoso, noturno ou em uma das "piores formas de trabalho infantil". Todo o tipo de trabalho que não respeitar as limitações de idade/legais é considerado trabalho infantil (CUSTÓDIO; MOREIRA, 2015, p. 69).

A proteção contra a exploração do trabalho infantil visa garantir o desenvolvimento integral de crianças e adolescentes, que estão passando por uma situação peculiar de pessoa em desenvolvimento, passando pelas mais diversas transformações, dentre elas as físicas, psicológicas, mentais, socioculturais. A exploração do trabalho infantil viola direitos fundamentais de crianças e adolescentes, como os direitos a educação, a saúde, ao lazer, a cultura, ao esporte, ao não trabalho abaixo da idade mínima, dentre outros. As limitações de idade para o trabalho visam possibilitar a garantia de tais direitos (CUSTÓDIO; MOREIRA, 2015, p. 87-88).

A prática do trabalho infantil gera as mais diversas consequências para o desenvolvimento integral de crianças e adolescentes. Do ponto de vista educacional, o trabalho infantil prejudica o desenvolvimento educacional, gerando déficits de atenção e evasão escolar. Do ponto de vista da saúde, o trabalho infantil traz consequências negativas a saúde quando exercido abaixo da idade mínima. Do ponto de vista econômico, o trabalho infantil gera exclusão social e a perpetuação do ciclo intergeracional da pobreza, que consiste 
na manutenção da situação de pobreza ou de extrema pobreza dos pais quando da vida adulta. $\mathrm{Na}$ sociedade contemporânea, quanto mais prematura for a exploração do trabalho infantil, piores serão as oportunidades futuras, o que decorre da grande competição por melhores oportunidades (CUSTÓDIO; MOREIRA, 2015, p. 89-95).

Mesmo com as diversas consequências, que estão comprovadas cientificamente por diferentes áreas do conhecimento, o trabalho infantil possui causas culturais enraizadas na sociedade. Diversas são as opiniões favoráveis ao trabalho infantil que são explanadas no dia a dia e que dificultam a sua erradicação. As opiniões favoráveis são utilizadas como justificativas para a manutenção da exploração de mão de obra infantil ou para o incentivo ao trabalho infantil. Tais conceitos são definidos como mitos, pois não condizem com a verdade sobre a temática, mas que são constantemente explanados pelos mais diversos membros de uma comunidade. Custódio e Veronese elencaram os mitos relacionados a exploração do trabalho infantil: "O primeiro mito: é melhor trabalhar do que roubar"; "O segundo mito: o trabalho da criança ajuda a família"; "O terceiro mito: é melhor trabalhar do que ficar nas ruas"; "O quarto mito: lugar de criança é na escola"; "O quinto mito: trabalhar desde cedo acumula experiência para o futuro"; "O sexto mito: é melhor trabalhar do que usar droga"; "O sexto mito: trabalhar não faz mal a ninguém”. (2013, p. 93-108).

Todas as frases expostas já foram desmistificadas pela ciência e não condizem com uma verdade, pois são claras as consequências negativas que o trabalho infantil traz para o desenvolvimento humano.

Assim, a permissividade cultural favorável ao trabalho infantil é um problema social no Brasil, sendo uma das principais causas para a exploração do trabalho infantil:

\footnotetext{
No plano cultural, aliás, verdadeiro mito que precisa ser combatido, mais grave no Brasil, é o fato de que o trabalho infantil, em suas variadas formas, para as crianças e os adolescentes pobres, carentes e humildes, sobretudo filhos de pais pobres e/ou desempregados deve ser permitido e mesmo incentivado para evitar a entrada na marginalidade infanto-juvenil (SOUZA, 2008, p. 98).
}

Em decorrência do exposto, verifica-se que se o direito social puro fosse utilizado no que diz respeito ao trabalho infantil, a sociedade iria desregulamentar as garantias obtidas em vista da cultura favorável a atividade por parte da sociedade, que utiliza de mitos. O direito social condensado é a teoria mais segura para abordar tal tema, tendo que se garantir os preceitos fundamentais previstos na Constituição Federal, tanto em relação a uma idade 
mínima para se iniciar a trabalhar, conforme prevê o artigo $7^{\circ}$, inciso XXXIII, quanto em relação a proteção integral prevista no artigo 227, por meio das teorias procedimentalistas e substancialistas. Ou seja, o respeito a Constituição Federal deve ser observado para a criação do direito nas comunidades, assim como haverá a intervenção por parte do Poder Judiciário quando essa não for respeitada.

\section{O RECONHECIMENTO DE DIREITOS HUMANOS DE CRIANÇAS E} ADOLESCENTES NOS MUNICÍPIOS POR MEIO DOS CONSELHOS DA CRIANÇA E DO ADOLESCENTE: O EMPODERAMENTO SOCIAL LOCAL E AS
ESTRATÉGIAS PARA O ENFRENTAMENTO AO TRABALHO INFANTIL

Em consonância com o direito social, o artigo 227 da Constituição Federal previu a tríplice responsabilidade compartilhada, que traz o dever do Estado, da família e da sociedade em garantir os direitos da criança e do adolescente para a garantia da proteção integral. A sociedade se encontra como protagonista nesse processo protetivo, devendo agir de forma atuante na proteção de direitos e na erradicação do trabalho infantil.

Os municípios são os locais onde deve ser construído o direito e desenvolvida as políticas públicas destinadas à infância. A participação social é fundamental para a melhor efetivação do direito. Os municípios são os locais que estão mais perto do destinatário final do direito, sendo que, em novos modelos de gestão, se deve primar pela participação ativa da sociedade civil na gestão municipal. Para tal finalidade, é necessária a participação dos cidadãos de uma comunidade no espaço local, tanto em relação a participação ativa nas decisões comunitárias, assim como no desenvolvimento dos orçamentos públicos, possibilitando o aumento da democracia no espaço local. Dessa forma, se possibilitaria uma aliança entre a participação popular e a política da descentralização, desenvolvendo-se uma gestão pública municipal mais democrática e com mais eficácia (SANTIM, 2010, p. 423-424).

Pelo fato de estar mais próximo do cidadão, o Poder Local é mais factível de ser democratizado e de oportunizar uma maior participação da comunidade. Mediante o espaço local são produzidas identidades próprias á pluralidade de sujeitos, criando um centro de poder político paralelo ao estatal - um espaço autônomo, formado, pela sociedade civil, numa nova relação desta com o Estado - e estabelecendo uma tensão permanente e deliberada como o governo de representação. (SANTIM, 2010, p. $424-425$ ) 
A atuação dos cidadãos nas decisões locais é importante para se buscar o autogoverno baseado na cidadania ativa, com a finalidade de se chegar ao bem comum e garantir o interesse público, de forma legítima. O sistema republicano possibilita que os cidadãos busquem um maior nível de satisfação de seus desejos de forma democrática e não arbitrária (AGRA, 2005, p. 17-19).

O republicanismo tem como uma de suas principais características o ideal de que "as decisões políticas são tomadas pela população, depois de amplo debate político que esclareça a temática abordada e permita uma escolha consciente" (AGRA, 2005, p. 69).

A construção articulada entre o poder público e a sociedade é uma necessidade quando se fala da instituição de políticas públicas em uma sociedade democrática.

\begin{abstract}
A escolha das políticas públicas em uma democracia é mais demorada; cada decisão, antes de ser tomada, deve ser precedida por intensos debates públicos, que proporcionam à população consciência a respeito dos assuntos que devem ser decididos. Sua vantagem é que quando as escolhas são realizadas, ostentam grau mais intenso de legitimidade que lhes garante sua eficácia. Em regime autoritário, as decisões podem ser tomadas com maior rapidez, entretanto, ao menor sinal de arrefecimento do poder de coerção que o mantém, sua legitimidade dilacera-se, bem como suas condições de governabilidade. (AGRA, 2005, p. 72)
\end{abstract}

As decisões tomadas após um debate democrático são fundamentais para o desenvolvimento comunitário democrático. A constância dos debates traz construções democráticas exitosas, que possibilitam o aperfeiçoamento das decisões políticas, pois a contradição é benéfica para a democracia, desde que sejam respeitados os resultados e sejam cumpridas as leis e as políticas públicas (AGRA, 2005, p. 73).

O poder local é fundamental para a aproximação entre os membros da sociedade e o Estado. Por meio dele se poderá chegar a um modelo mais democrático e participativo, possibilitando a atuação de forma concreta na construção do direito social e das políticas públicas, sendo possível que se atue "[...] apossando-se dos espaços públicos, não apenas de decisão política, mas de fiscalização e concreção das tarefas do Estado [...]”, e possibilitando "[...] revitalizar o poder local, explorando suas potencialidades captando o capital social e humano por meio das políticas públicas” (HERMANY; DUPONT, 2014, p. 3).

A realização de políticas públicas na esfera local potencializa o sentimento de pertencimento dos cidadãos as comunidades, estimulando a participação efetiva do processo decisório relacionado à esfera municipal, assim como possibilitando a contribuição social responsável, bem como o conhecimento de direitos e responsabilidades por parte dos atores 


\section{A aplicabilidade da teoria do direito social de Gurvitch no reconhecimento de direitos humanos de crianças e adolescentes: estratégias para o enfrentamento ao trabalho infantil nos municípios brasileiros}

sociais. O processo decisório compartilhado entre a sociedade e a administração pública, contribui para a transparência e efetividade de políticas públicas, garantindo, ainda, a articulação entre os interesses públicos e privados (HERMANY; et. al., 2005, p. 1.410-1.411).

Os Conselhos de Direitos da Criança e do Adolescente são órgãos estatais que possuem a participação da sociedade e estão presentes no âmbito federal, estadual e municipal, tendo como função o planejamento da efetivação de direitos humanos de crianças e adolescentes. Em consequência, aos conselhos cabe a deliberação em cada nível federativo. O Conselho Nacional dos Direitos da Criança e do Adolescente (Conanda) tem por objetivos:

Ao CONANDA compete elaborar as normas gerais da política nacional de atendimento dos direitos da criança e do adolescente, fiscalizando as ações de execução; zelar pela aplicação da política nacional de atendimento dos direitos da criança e do adolescente; apoiar a promoção de campanhas educativas sobre os direitos da criança e do adolescente, com a indicação das medidas a serem adotadas nos casos de atentados ou violação dos mesmos. (BRASIL, 2011, p. 5)

Dentre as diretrizes dessa política estão: a busca pela construção de redes de ações integradas e a descentralização da política de atendimento de crianças e adolescentes, onde se incentiva a integração com a comunidade. Aos Conselhos compete: "deliberar e controlar o conjunto de políticas públicas básicas, dos serviços especializados e de todas as ações governamentais e não governamentais direcionadas para o atendimento da criança e do adolescente" (CUSTÓDIO; VERONESE, 2013, p. 165-176).

$\mathrm{O}$ atendimento destinado a garantir o acesso à saúde, à educação, à assistência social, à cultura, ao esporte e ao lazer visa também atuar contra a prática do trabalho infantil, trazendo estratégias interdisciplinares para o enfrentamento de tal prática. Neste sentido, deverão ser instituídas pelos Conselhos Municipais estratégias que demonstrem a necessidade de articulação entre as políticas públicas, construindo uma rede articulada de proteção integral aos direitos humanos e fundamentais.

O artigo 88 do Estatuto da Criança e do Adolescente dispõe as diretrizes para o desenvolvimento de políticas públicas de atendimento de crianças e adolescentes no Brasil:

Art. 88. São diretrizes da política de atendimento:

I - municipalização do atendimento;

II - criação de conselhos municipais, estaduais e nacional dos direitos da criança e do adolescente, órgãos deliberativos e controladores das ações em todos os níveis, assegurada a participação popular paritária por meio de organizações representativas, segundo leis federal, estaduais e municipais; 
III - criação e manutenção de programas específicos, observada a descentralização político-administrativa;

IV - manutenção de fundos nacional, estaduais e municipais vinculados aos respectivos conselhos dos direitos da criança e do adolescente;

V - integração operacional de órgãos do Judiciário, Ministério Público, Defensoria, Segurança Pública e Assistência Social, preferencialmente em um mesmo local, para efeito de agilização do atendimento inicial a adolescente a quem se atribua autoria de ato infracional;

VI - mobilização da opinião pública no sentido da indispensável participação dos diversos segmentos da sociedade;

VI - integração operacional de órgãos do Judiciário, Ministério Público, Defensoria, Conselho Tutelar e encarregados da execução das políticas sociais básicas e de assistência social, para efeito de agilização do atendimento de crianças e de adolescentes inseridos em programas de acolhimento familiar ou institucional, com vista na sua rápida reintegração à família de origem ou, se tal solução se mostrar comprovadamente inviável, sua colocação em família substituta, em quaisquer das modalidades previstas no art. 28 desta Lei;

VII - mobilização da opinião pública para a indispensável participação dos diversos segmentos da sociedade. (BRASIL, 1990)

Portanto, os Conselhos de Direitos da Criança e do Adolescente são órgãos que atuam no desenvolvimento do direito no âmbito municipal para aperfeiçoar as políticas públicas de atendimento, com o intuito de inclusão social na esfera local, sendo sua a incumbência de capacitação de toda a rede de atendimento municipal à criança e ao adolescente e dos executores do Sistema de Garantia de Direitos de Crianças e Adolescentes, possibilitando a articulação entre o Sistema de Garantia de Direitos e as políticas públicas de atendimento em todas as esferas.

\section{CONSIDERAÇÕES FINAIS}

Constatou-se que o direito social condensado poderá ser utilizado sempre que observado o referencial mínimo constitucional o que possibilitaria a participação social nas decisões públicas em um determinado município, sendo um modelo que auxilia na proteção dos direitos humanos e fundamentais de criança e adolescentes que são violados com a exploração do trabalho infantil.

Para a obtenção de uma melhor efetivação da erradicação do trabalho infantil se faz necessário ações articuladas entre a sociedade, as famílias e o Estado, visando possibilitar a proteção integral dos direitos da criança e do adolescente, por meio da atuação dos Conselhos Municipais de Direitos da Criança e do Adolescente.

Conclui-se, também, que a teoria do direito social condensado traz melhores possibilidades de desenvolver o processo de erradicação do trabalho infantil, estando de 
acordo com as diretrizes nacionais de efetivação de direitos de crianças e adolescentes, tendo por base a Constituição Federal, tanto em relação a uma idade mínima para se iniciar a trabalhar, conforme prevê o artigo $7^{\circ}$, inciso XXXIII, quanto em relação a proteção integral prevista no artigo 227.

Por fim, verificou-se compatibilidade entre a atuação dos Conselhos Municipais de Direitos da Criança e do Adolescente e a teoria do direito social condensado, pois a construção e o reconhecimento do direito nos municípios depende de participação da sociedade e as deliberações devem estar de acordo com o que prevê a Constituição Federal.

\section{REFERÊNCIAS}

AGRA, Walber de Moura. Republicanismo. Porto Alegre: Livraria do Advogado, 2005.

BRASIL. Consolidação das Leis Trabalhistas. 1943. Disponível em: <http://www.planalto.gov.br/ccivil_03/decreto-lei/del5452.htm> Acesso em: 25 jun. 2016.

Constituição da República Federativa do Brasil. 1988. Disponível em:

<http://www.planalto.gov.br/ccivil_03/constituicao/constitui\%C3\%A7ao.htm> Acesso em: 25 jun. 2016.

Estatuto da Criança e do Adolescente. 1990. Disponível em:

<http://www.planalto.gov.br/ccivil_03/leis/18069compilado.htm> Acesso em: 25 jun. 2016.

Lei n. 10.097. 2000. Disponível em:

<http://www.planalto.gov.br/ccivil_03/leis/L10097.htm> Acesso em: 05 jul. 2016.

Plano Nacional de Prevenção e Erradicação do Trabalho Infantil e Proteção do Adolescente Trabalhador. Comissão Nacional de Erradicação do Trabalho Infantil. 2. ed. Brasília : Ministério do Trabalho e Emprego, 2011.

CUSTÓDIO, André Viana; VERONESE, Joseane Rose Petry. Trabalho Infantil Doméstico. São Paulo: Saraiva, 2013.

; MOREIRA, Rafael Bueno da Rosa. Exploração Sexual Comercial de Crianças e Adolescentes: Reflexões Contemporâneas no Contexto do Brasil, da Argentina e do Uruguai. Curitiba: Multideia, 2015.

GURVITCH, Georges. La Idea del derecho social. Granada: Comares, 2005.

HERMANY, Ricardo. (Re) Discutindo o Espaço Local: uma abordagem a partir do direito social de Gurvitch. Santa Cruz do Sul: Edunisc, 2007.

; DUPONT, Fabiano Rodrigo. O poder local e o fortalecimento das comunidades: a articulação necessário entre capital social, pertencimento e cooperação. In: SEMINÁRIO 
INTERNACIONAL DE DEMANDAS SOCIAIS E POLÍTICAS PÚBLICAS NA SOCIEDADE CONTEMPORÂNEA, 11, 2014, Santa Cruz do Sul. Anais eletrônicos. Santa Cruz do Sul: UNISC, 2014.

; et. al., O princípio da subsidiariedade e o direito social de Gurvitch: a ampliação das competências municipais e a interface com a sociedade. In: LEAL, Rogério Gesta; REIS, Jorge Renato (organizadores), Direitos Sociais e Políticas Públicas: Desafios contemporâneos. Santa Cruz do Sul: EDUNISC, 2005.

MINHARRO, Erotilde Ribeiro dos Santos. A criança e o adolescente no Direito do Trabalho. São Paulo: LTr, 2003.

MORAES, José Luiz Bolzan de. A idéia de direito social: O pluralismo de Georges Gurvitch. Porto Alegre: Livraria do Advogado, 1997.

OLIVA, José Roberto Dantas. O princípio da proteção integral e o trabalho da criança e adolescente no Brasil. São Paulo: LTr, 2006.

ORGANIZAÇÃO DAS NAÇÕES UNIDAS - ONU. Convenção sobre os Direitos das Crianças. 1989. Disponível em < http://www.planalto.gov.br/ccivil_03/decreto/19901994/D99710.htm>. Acesso em: 28 jun. 2016.

ORGANIZAÇÃO INTERNACIONAL DO TRABALHO - OIT. Convenção 138 sobre a idade mínima de admissão ao emprego. 1973. Disponível em:

<http://white.oit.org.pe/ipec/pagina.php?seccion=47\&pagina=156> Acesso em: 29 jun. 2016.

Convenção 182 sobre a proibição das piores formas de trabalho infantil e ação imediata para sua eliminação. 1999. Disponível em:

<http://www.ilo.org/public/spanish/standards/relm/ilc/ilc87/com-chic.htm> Acesso em: 29 jun. 2016.

RESTA, Eligio. Tempo e Processo. Santa Cruz do Sul: Essere nel Mondo, 2014.

SANTIN, Janaina Rigo. Poder Local e Gestão Democrática Municipal: uma análise a partir da teoria do discurso em Jurgen Habermas. In: HERMANY, Ricardo (organizador).

Empoderamento Social Local. Santa Cruz do Sul: IPR, 2010.

SANTOS, Boaventura de Souza. Para uma revolução democrática da justiça. Cortez, 2008.

SOUZA, Jadir Cirqueira de. A efetividade dos direitos da criança e do adolescente. São Paulo: Pillares, 2008.

SPENGLER, Fabiana Marion. Retalhes de mediação. Santa Cruz do Sul: Essere Nel Mondo, 2014. 